\title{
Environmental Object Based Method for Electrical Engineering Subjects to Enhance Learning and Teaching
}

\author{
Ka Wai E. Cheng and Weimin Wang
}

\begin{abstract}
Environmental protection is now an important area of study as well as the global concern. Many teaching and learning may involve the environment as part of their study. In engineering, there are many topics related to them, but most of the syllabus may too theoretical and it is necessary to develop an object based method to assist students' learning. A demonstration of the environmental protection and energy saving concept to Outcome-based education through a web-site development has been successfully made. A vertical and horizontal link of the environmental aspects to the study have been used in the development. It enhances the student's learning and has provided linkage and correlation among various subject areas.
\end{abstract}

Index Terms-Environmental protection, energy saving, engineering, environmental based teaching, object based learning.

\section{INTRODUCTION}

Energy saving and environmental protection is a necessary concept for most of the electrical engineering subjects. This is also the common objective of most subjects. However, the syllabus of the subject is rather theoretical and students may not really understand the application, case study, and some simple demonstration units. There is now a strong need of the environmental based teaching as used in the general teaching. The use of electronics books [1] have been popular in the past of enhancing the study in which better illustration and animation can be found, however they are not problem or output based teaching. The problem-based laboratory [2] has also been reported for undergraduate study. Ref [3] reports of use of levels of knowledge structure for problem-based learning. However, most of problem-based learning is only restricted to a particular subject and there is no linkage among different subjects. The classical method of object based teaching, problem based teaching [4]-[7] should be revised in order to fit in this new challenge of teaching method.

The needs also connected with their future career as a large portion of the jobs today are strongly related to energy saving and environmental protection. It is necessary to strengthen the understanding of this area. The formal lecture is not able to cover all these areas. However, these areas have been covered in mini-project and internet.

Manuscript received September 10, 2012; revised January 4, 2013. This work was supported in part by the Learning and Teaching Committee of the HK Polytechnic University under Grant 464F.

K. W. E. Cheng and W. M. Wang are with the Department of Electrical Engineering, The Hong Kong Polytechnic University (e-mail: eeecheng@polyu.edu.hk, eewmwang@polyu.edu.hk).
Department of Engineering has offered a number of power related objects, many of them has substantial content in environmental and energy saving. However, the students and the lectures may not have time to cover all the contents and how to extend the concept of the environmental protection and energy saving derived form the lecture and beyond the learning.

On the other hand, OBE is a student-centered learning philosophy that focuses on empirically measuring student performance, which is called outcome. OBE contrasts with traditional education, which primarily focuses on the resources that are available to the student, which are called inputs. As the EE subjects are all partly related to energy saving and environmental protection, this outcome should be mastered by students, but with the limited resources and lack of previous project as references, and no professional comment in all these information, students will have difficulty to achieve the learning outcomes. Conventional use of web-based teaching [6], [7] can be modified to include the environmental teaching and it will also provide an additional resource for the students' learning.

This paper is to describe how to develop the outcome based materials that facilitate the students to know more in the areas of:

- Environmental protection

- Energy saving

- Zero emission

- Low carbon environment.

- How the impact of the electrical engineering can help these areas

Form them, a link can be developed to relate all the similar topics in different subjects and to develop the correlation and examples among them. This correlation is very useful top enhance the students' learning.

\section{THE DEVELOOPMENMT IN OBM}

\section{A. The Website Development}

A web site and list of computerized materials will be developed. It will link to a number of courses in the electrical engineering. It identifies the content in the above areas. A link of related the energy saving and environmental protection among the subjects will be developed. It will provide additional information on:

- Industrial application

- How a student to perform further

- Relevant work done in the public and overseas

- Extend the study in the lecture to the environmental areas 
The advantage of the development will

- Extend the book knowledge to practical use

- Help students to build up applications

- Develop a real link between university study and industry

- Find out then interlink and intralink between subjects and beyond study.

- Provide the project and cases study to students.

- Provide outcome based education in the aspect of energy saving and environmental protection.

\section{B. Intended Learning Outcomes for Students}

A student should be able to find out suitable solutions for a particular industrial application through past cases, demonstration kits and web. A direct method is developed to let student realize the difference between knowledge and real based application

This is a way to apply and to demonstrate academic knowledge by cases and projects. A student should able to find out the information they need through the website and past reports. Students will have the practical information of the content of energy saving and environmental protection in the subjects. Cases study will be developed.

The teaching subjects in electrical engineering in the areas of these fields are firstly aim to the following 4 subjects as shown in Table I.

TABLE I: THE TARGET USERS OF THE PROPSOED ENVIRONENTAL OBM

\begin{tabular}{l|l|l|l}
\hline \hline $\begin{array}{l}\text { Subject } \\
\text { Code }\end{array}$ & Programme/subject title & $\begin{array}{l}\text { Credit } \\
\text { units }\end{array}$ & $\begin{array}{l}\text { Average student } \\
\text { in-take per year }\end{array}$ \\
\hline EE530 & $\begin{array}{l}\text { Electrical Energy Saving } \\
\text { System }\end{array}$ & 3 & 106. \\
\hline EE543 & $\begin{array}{l}\text { Hybrid and Electric Car } \\
\text { Technology }\end{array}$ & 3 & 15 \\
\hline EE4211 & $\begin{array}{l}\text { Advanced Power } \\
\text { Electronics }\end{array}$ & 3 & 30 \\
\hline EE4021 & Electrical Machines & 3 & 110 \\
\hline
\end{tabular}

\section{HOW TO IMPLEMENTAL ENVIRONMENTAL OBE}

Because the syllabus of each subject has a number of content in energy saving and environmental projection, the method is firstly to pick the area that is directly related to the environment. A number of articles, diagrams and the hyperlinks are then developed to enhance student learning. The mechanism that is developed in each of the subject is as follows:

\section{A. Electrical Energy Saving System}

The basic idea of the subject is classified into 4 main areas of energy saving. They are energy storage systems, solar energy utilization, energy saving control and monitoring systems and fluorescent lighting, ballast and variable speed drives.

A number of examples for the above areas are provided in the web sites. The subject EE530 Electrical Energy Saving System has covered the detail topic of this field.

\section{B. Environmental Protection}

The basic related to these areas includes the subject EE543 Hybrid and Electric Car Technology. The support subject is the EE4211 Advanced Power Electronics and EE4021 Electrical Machines which provides various topics for the field.

\section{EXAMPLE OF Web Site DEVELOPMENT}

The Website is firstly classified into a number of electric energy saving and environmental protection pages. Two sub-pages will be shown firstly. One is the energy saving and another is the environmental protection.

\section{A. Energy Saving}

The energy saving is firstly introduced by talking the basic theory of the energy saving, The energy saving theory is not just to reduce the use of the electrical apparatus, but to propose method to reduce the loss through suitable operation or advanced techniques. The reduction of the duration of usage and the reduction in performance are not energy saving as they only reduce the energy consumption through providing reduction of services. The proper method of energy saving is to propose more advanced method or to operate the apparatus in a way to improve its efficiency without reduction of its performance. The website will firstly show the basic element in energy saving. The first one to introduce is the motor operation. It will firstly introduce the energy saving system scheme in motor. Motor is strictly related to energy consumption as all the air-conditioning, and moving parts are motor related loss. Fig. 1 shows the motor characteristics under the variable sped drives which enable the motor to operate los slip condition.

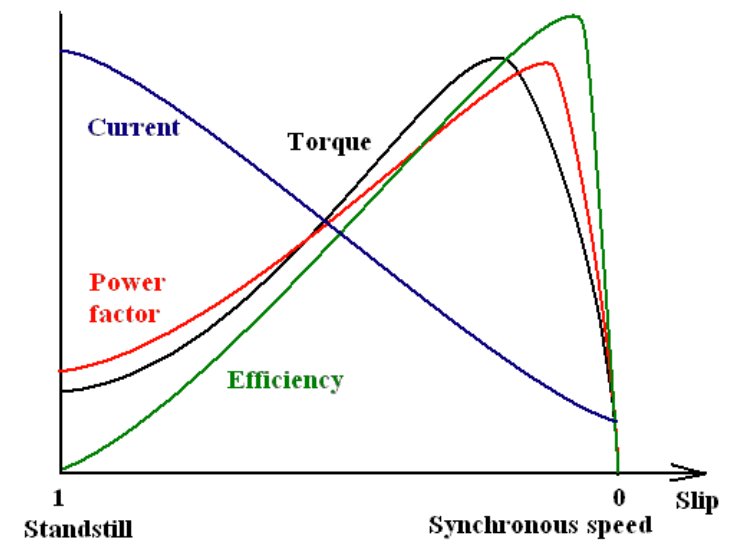

Fig. 1. Motor operation under VSD for energy saving.

The next system is to introduce is the lighting. The basic energy saving in energy saving is the use of fluorescent lamp to replace the conventional incandescent lamp.

The second level of energy saving in lighting is to use electronic ballast to replace the magnetic ballast. The variation of this type also includes the compact fluorescent Lamp (CFL). The third level of energy saving is to use LED to replace the electronic ballast operated fluorescent tube.

The Web site also describes the basic power electronics circuit [8]. The circuit used in this energy saving section is to describe the power converter for use in electronic ballast. It also explains the LED circuit operation. The basic circuit in LED driver is firstly explained. The variation in circuit for more advanced LED driver is also presented. Fig. 2 shows the basic electronic ballast for fluorescent lamp. Fig. 3 shows the series of the LED circuits. From the circuits, students will have an understanding the basic driving circuit for the LED 
lighting system. They will also understand the correlation of the LED driver to the basic power electronic converter.

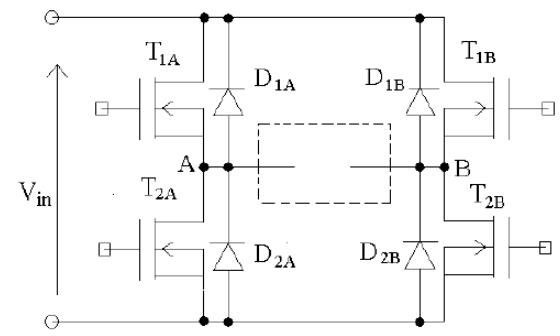

Fig. 2. The fundamental circuit for electronic ballast.

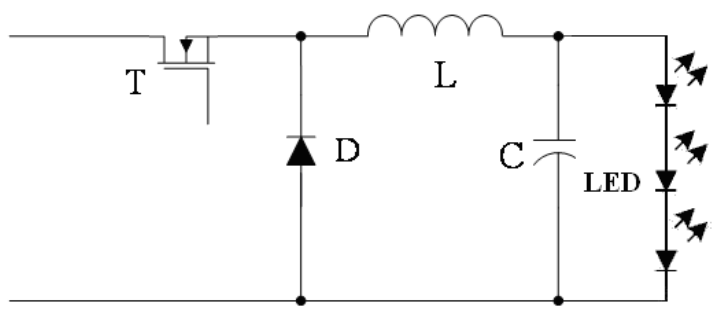

(a) LED Buck converter

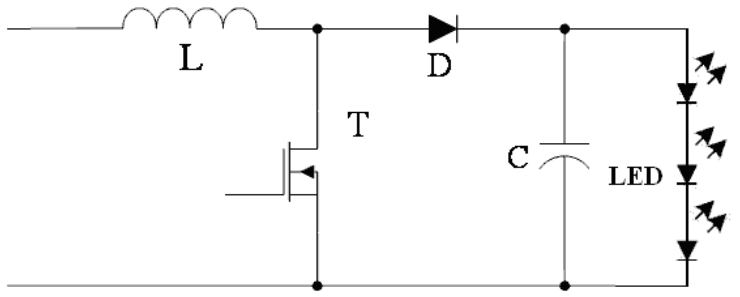

(b) LED Boost converter

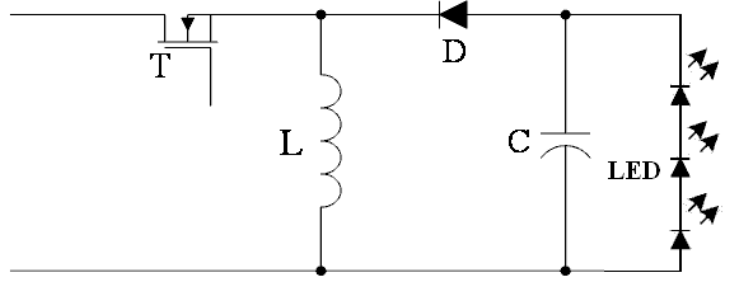

(c) LED Buck-Boost converter

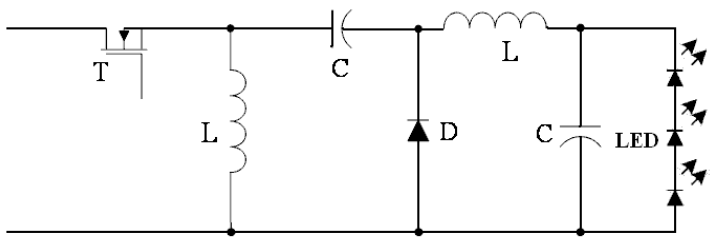

(d) LED Cuk converter

Fig. 3. Energy saving for LED connection.

\section{B. Environmental Protection}

The web section for environmental protection is to describe the teaching method of above subjects as shown in Table I and how they will be related to the environmental protection. The topics to be introduced includes the

1) Electric vehicle.

2) Energy storage system

3) Motor

\section{1) Electric vehicle}

Electric vehicle is a combination of advanced power electronics and electrical machines. Fig. 4 shows a basic structure of an electric vehicle. The parts and components of an electric vehicle include the battery, motor, motor driver, charger and DC-DC converter. These components are taught in more details through the subjects EE543 Hybrid and Electric Car Technology, EE4211 Advanced Power Electronics and EE4021 Electrical Machines.

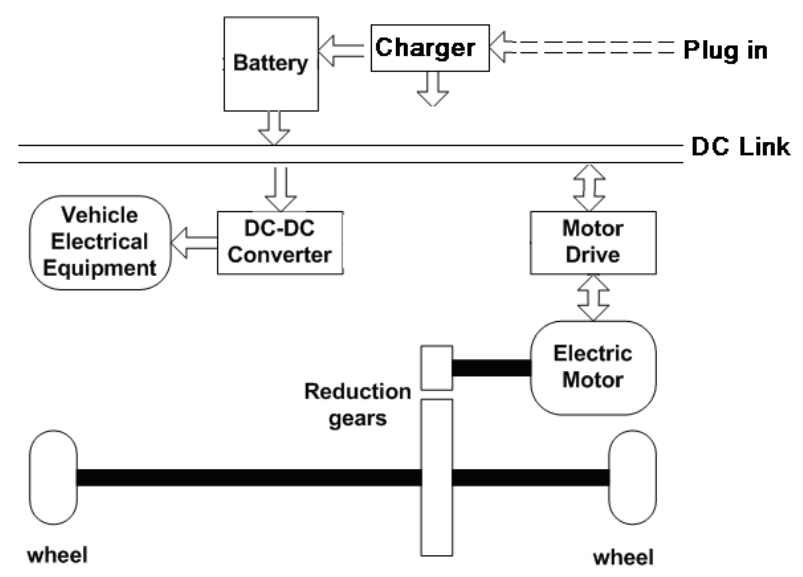

Fig. 4. Electric vehicle schematic.

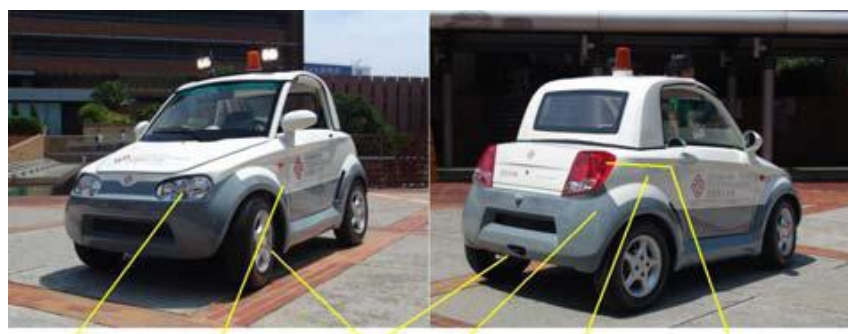

HID front lightings DC Converter Motor drive Battery Integrated charger LED Rear lighting

Fig. 5. The typical components in an electric vehicle.

For examples, the DC-DC converter is part of the teaching in the chapter of classical DC-DC converter of EE4211 and motor drive is part of EE4021.

\section{2) Energy storage system}

The energy storage system is to store energy during the energy source is available and its energy is discharged to the load in another time. The energy storage system mainly refers to rechargeable battery and super-capacitor for electrical system. They can also be applied to electric vehicles, solar power and wind power. The webpage will show a collect of various battery types. Fig. 6 shows various types of batteries.

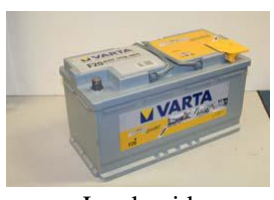

Lead-acid

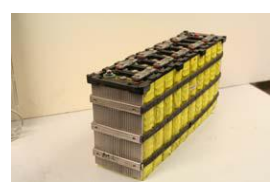

$\mathrm{NiMH}$

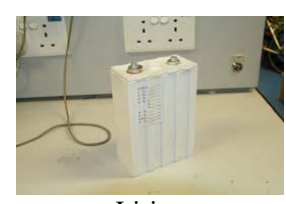

Li-ion
Fig. 6. Various energy storage batteries.

Battery management system (BMS) is a necessary part for use together with battery.

The battery management system has recent attention recently due to the popularity of the renewable energy. Most of the renewable energy system uses battery or other energy storage units. The electronic circuit for this supporting unit called the BMS which is a necessary component for the safety, optimal operation and fully utilization of the state of charge. Fig. 7 shows a typical circuit for the BMS. 


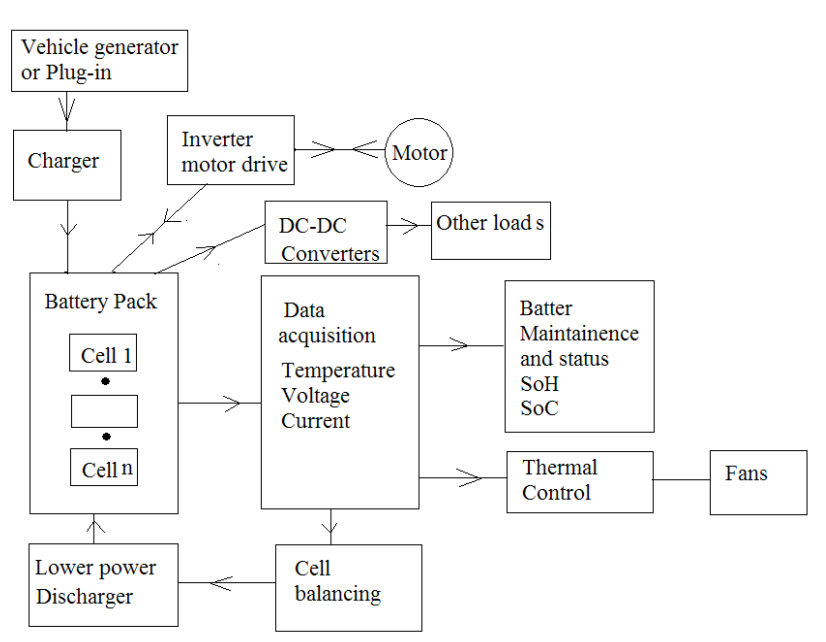

Fig. 7. Typical BMS system diagram.

\section{3) Motor}

Motor is an important energy unit in the electrical market. Motor can be used in air-conditioning system, water pump, electric vehicle, industrial machinery, transportation system and many units that need motion control. It accounts for $50 \%$ to $80 \%$ for energy consumption in different cities. The Web site development will present the motor types, the application, and driver circuit. Fig. 8 shows a typical switched-reluctance motor.

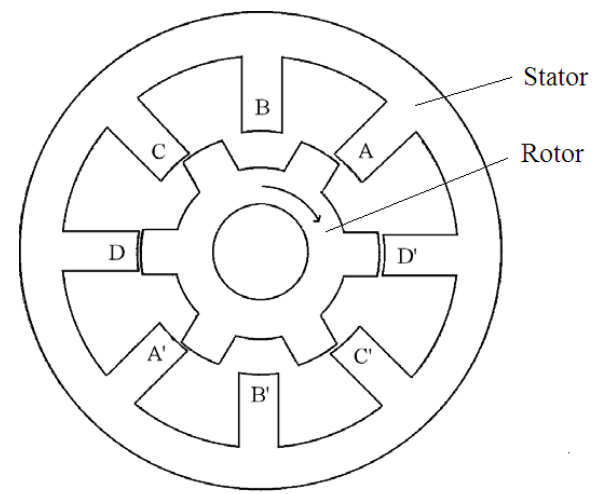

Fig. 8. An 8/6 switched reluctance motor.

There are also many different types of motor and they can also be used in the environmental friendly system. Fig. 9 shows a special motor which is an in wheel motor with a motor inside a wheel for electric vehicle application. The rotor and the stator are inside out as compared to Fig. 8. This is a strong correlation between motor drive, motor, electric vehicle, environmental saving.

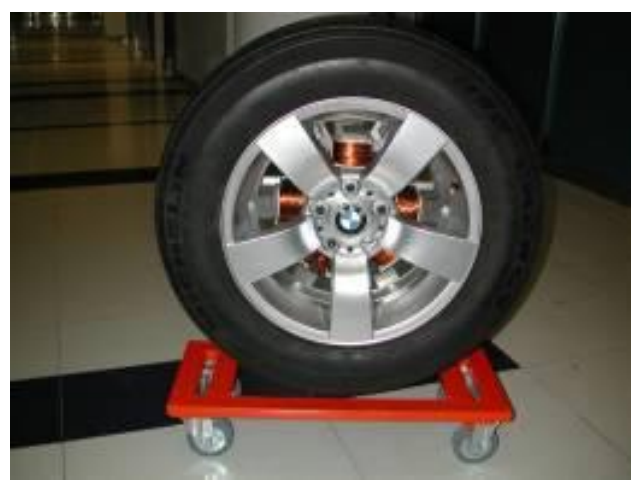

Fig. 9. An in-wheel motor developed for electric vehicle.
Fig. 10 shows the vertical and horizontal integration of the environmental object based method that is linked to each sub-topic in the web-design. The subjects are designated by the EE530, 543, 4021 and 4211.

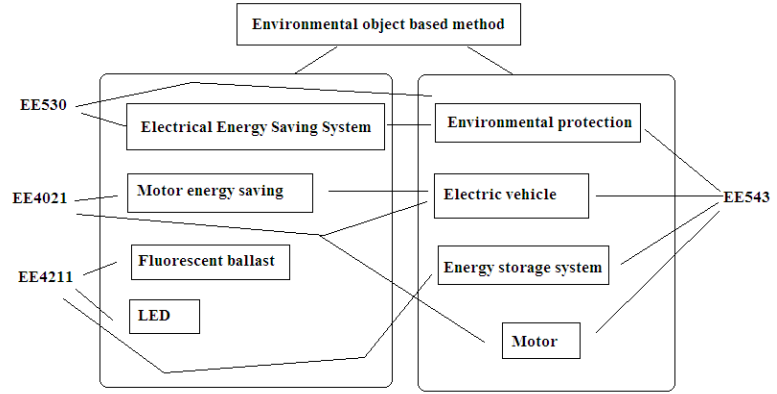

Fig. 10. The integration of the web-design for the environmental-object based.

Initial link is developed for the web-page, there are more links and flows will be added to them. More case study, example and theory are added to enrich the data base for the environmental protection study. It is anticipated that a large matrix network will be developed for such object development.

\section{BENEFIT TO STUDENTS}

The student through this web-site developed can now fully understand the interlinked between each subject. The similarity among the subject can be examined and studied in vertical and horizontal means. In the past many contents are designed independently and there is no link among them. Today, as the environmental based topics are now across the multiple disciplines, the correlation of the subject areas can be demonstrated by the proposed method. The web site can be designed by the method and the added advantage for the student will be a better understanding of the subjects.

The study has examined the correlation of circuit, motor, energy storage, driver and lighting among the different subjects. There is a link developed between the subjects advanced power electronics and the electrical energy saving system. The electric motor is also used in the development of a link between the subject electrical machines and the Hybrid and Electric Car Technology. More links to enhance the learning has also been developed. The above are only parts of examples.

\section{CONCLUSION}

An environmental based teaching method is presented. The proposed method in environmental-object based teaching g using a web site is extremely useful to enhance student learning. Through the posed 4 subjects, we have developed the link of the subject in vertical and horizontal. Student now has a better understanding of the correlation of the environmental protection aspects of the subject.

\section{ACKNOWLEDGMENT}

The authors acknowledge the support of the Learning and Teaching Committee of the Hong Kong Polytechnic 
University under the Small Scale Learning \& Teaching Development Project of the project P464F.

\section{REFERENCES}

[1] K. W. E. Cheng, "Exploring problem based learning techniques in electromagnetic computation," in Proc. Compumag'2001, Evian, France, vol. 4, pp. 116-117.

[2] K. E. Bledsoe and L. Flick, "Concept Development and Meaningful Learning Among Electrical Engineering Students Engaged in a Problem-Based Laboratory Experience," Journal of Science Education And Technology, vol. 21, issue 2, pp. 226-245, April 2012.

[3] B. Galand, M. Frenay, and B. Raucent, "Effectiveness of Problem-Based Learning in Engineering Education: A Comparative Study on Three Levels of Knowledge Structure," International Journal of Engineering Education, vol. 28, issue. 4, pp. 939-947, 2012.

[4] K.W. E. Cheng, "Web-based inductor design program for engineering students," Compumag'2001, Evian, France, vol. 4, pp. 118-119.

[5] K. W. E. Cheng, V. Y. T. Mok, X. D. Xue, and K. W. Chan, "Discussion of Problem-Based Learning for Teaching Advanced Power Electronics Techniques in a Laboratory Setup," EPE, Graz, Austria, August, 2001.

[6] K. W. E. Cheng and S. C. Cheung, " Our Experience on Mini-project and Web-based Information to Examine PBL for the Electrical Engineering Students," in Proc. Asia-Pacific Conference on PBL2001, Dec. 2001, pp. 57-66.

[7] K. W. E. Cheng, S. C. Cheung, S. K. Lee, and S. Chu, "Development of web-based interactive exercise for engineering student," ILEC 2001, December 2001, The H.K. Institute of Education, pp. 14.

[8] K. W. E. Cheng, Classical switched mode and resonant power converter, The Hong Kong Polytechnic University, 2001, ch. 2.

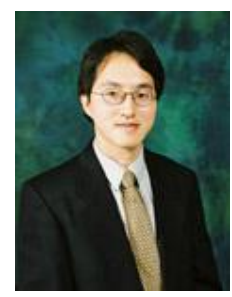

K. W. E. Cheng obtained his BSc and $\mathrm{PhD}$ degrees both from the University of Bath in 1987 and 1990 respectively. Before he joined the Hong Kong Polytechnic University in 1997, he was with Lucas Aerospace, United Kingdom as a Principal Engineer and led a number of power electronics projects.

He received the IEE Sebastian Z De Ferranti Premium Award (1995), outstanding consultancy award (2000), Faculty Merit award for best teaching (2003) from the University, Faculty Engineering Industrial and Engineering Services Grant Achievement Award (2006) and Brussels Innova Energy Gold medal with Mention (2007), Faculty Merit Award (2009) and Geneva's Invention Expo Silver Medal (2011). He has published over 250 papers and 7 books. He is now the professor and director of Power Electronics Research Centre of the university. His research interests are all aspects of power electronics, motor drives, EMI and energy saving.

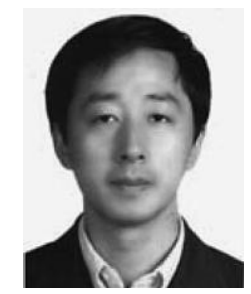

Weimin Wang was born in China. He received the B.Eng. and M.Eng degrees from Sichuan University, Chengdu, China, in 1994 and 1997, respectively, and the D.Eng. degree in mechanical engineering from South China University of Technology, Guangzhou, China, in 2000.

Currently, he is a research associate in the Department of Industrial and Systems Engineering at The Hong Kong Polytechnic University, Hong Kong. His current research interests include electromagnetic field analysis for rotating electric machines, motor drives, converters and structural analysis. 